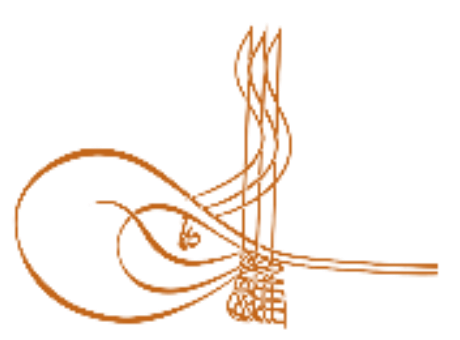

www.turkishstudies.net/turkishstudies
Turkish Studies

eISSN: $1308-2140$

Research Article / Araştırma Makalesi

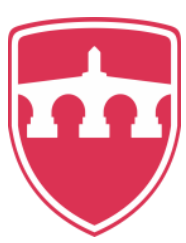

INTERNATIONAL

BALKAN

UNIVERSITY

Sponsored by IBU

\title{
Mimar Sinan'in Dörtlü Baldaken Sistemli Tek Kubbeli Camilerinde Görülen Farklı Mekan Kurguları
}

\author{
Different Space Organization In The Square Baldachin Single-Domed Mosques Of Architect Sinan
}

\author{
Alev Erarslan ${ }^{*}$
}

\begin{abstract}
The Ottoman Empire's Master Architect (Mimar) Sinan produced close to 400 works of different types, including mosques, hammams or bath-houses, madrasahs, masjids (prayer rooms), khans (inns), caravanserais, hospitals (darüşşifa), imarets, guest houses (tabhane), Koranic schools (darülkurra), primary schools (slbyan mektebi), waterways, lodges (tekke), fountains and palaces. The works of Mimar Sinan that he attached great importance to and produced the greatest in number were mosques. Sinan built mosques at different locations throughout the Empire, particularly in the capital city of Istanbul but he never used the same layout plan in any of these, never repeated himself, choosing instead to experiment continuously with different schemes. The dome is the fundamental building element that Sinan uses in his mosques. The dome is the principal component that determines the plan of the mosque, where it appears as an architectural feature that dominates the entire inner space as well as the outer plastic form. The dome is also a symbolic element that defines the city silhouette, standing at the center of the structure, becoming a significant part of the architectural landscape. With his mosques, Sinan has given the tradition of the domed structure a new identity and has developed a distinctive architectural style. The principal structural element that Sinan employed in his mosques was the dome. The construct of Sinan's mosque plans determined the structural characteristics that would constitute his domes. Mimar Sinan used use of multiple-support systems such as 4, 6 and 8-baldachins in his dome structures, planning the layouts of his domed structures around the framework of these systems. In this article, we will attempt to examine five of Mimar Sinan's square baldachin, single-dome mosques (Edirnekapı Mihrimah Sultan, Eyüp Zal Mahmut Pasha, Lüleburgaz Sokullu Mehmet Pasha, Fatih Bali Pasha and Manisa Muradiye) in an effort to offer an analysis on the organization of the domed principal and auxiliary spaces in these structures.
\end{abstract}

Structured Abstract: The Ottomans' Master Architect Koca Sinan produced a wide range of works in a variety of typologies that included mosques, hammams or bath-houses, madrasahs, masjids (prayer rooms), caravanserais, hospitals (darüş̧̧ifa), imarets, guest houses (tabhane), Koranic schools (darülkurra), and primary schools (sıbyan mektebi), leaving behind an expansive legacy. Mosques were the constructions that Mimar Sinan attached the most importance to and it was these that he planned in the greatest number. Sinan

\footnotetext{
* Doç.Dr., Istanbul Aydın Universitesi, Mimarlık ve Tasarım Fakültesi, Mimarlık Bölümü Assoc.Prof. Dr., Istanbul Aydin University, Faculty of Architecture and Design, Department of Architecture ORCID 0000-0003-2458-8788

aleverarslan@gmail.com

Cite as/ Atıf: Erarslan, A. (2020). Mimar Sinan'in dörtlü baldaken sistemli tek kubbeli camilerinde görülen farklı mekan kurgular1, Turkish Studies, 15(2), 943-958. https://dx.doi.org/10.29228/TurkishStudies.41660

Received/Geliş: 07 February/Şubat 2020

Checked by plagiarism software

Accepted/Kabul: 25 April/Nisan 2020

Published/Yayın: 30 April/Nisan 2020

Copyright (C) MDE, Turkey

CC BY-NC 4.0
} 
built mosques at different locations throughout the Empire, particularly in the capital city of Istanbul but he never used the same plan scheme in any of these, he never repeated himself, choosing instead to experiment continuously with different plans and structures.

The principal structural component in Sinan's mosques was the dome. The dome was the principal element he used in determining the plans for his mosques and this structure became an architectural component that dominated not only the entirety of the space but also the outer plastic of the building. At the same time, as a determining factor in the city's silhouette and in its central position in the structure, the dome also stood as a symbolic representation in Sinan's mosques. Sinan's mosques are important parts of the architectural landscape and it can be seen that Sinan assigned a new identity to the tradition of domed structures, in fact creating a new architectural style. It can be said that domed structures matured in Sinan's hands and gained new meaning and identification.

Mimar Sinan made use of many different variations of dome in his mosques. The structure and functionality was different in each of his mosques and therefore he treated the dome and consequently the spaces differently. It was these elements that determined the plan in this system and the dome was treated with a formalistic approach. Structural principles predominate in this design. Basically the product of a tectonic approach, the dome is the main element of the spatial arrangement in this construct. It was the construct of Sinan's mosque plans that determined the structural characteristics that would form his domes.

The nucleus of space in Sinan's mosques is the domed baldachin. The structural system of the baldachin is a construct that consists of a space, different numbers and variations of load-bearing elements (columns, piers, wall piers, corner wall) that carry the dome, which acts as a covering over the space. The plan and the space is formed around the baldachin. The system allows for a rich spatial construct and a variety of spatial variations are thus made possible. Mimar Sinan experimented with many different dome structures in his mosques and the construct of his mosque plans defined the structural characteristics of the domes he designed. Mimar Sinan made use of multiple-support systems of sometimes four, six or eight elements in his dome structures, planning the layouts of his domed buildings around the framework of these systems.

In this article, we selected a group of Mimar Sinan's square baldachin, single-domed mosques (Edirnekapı Mihrimah Sultan, Eyüp Zal Mahmut Pasha, Lüleburgaz Sokullu Mehmet Pasha, Fatih Bali Pasha, Kayseri Kursunlu ve Manisa Muradiye), attempting to examine these structures in terms of the central square baldachin system on which the domes rest as well as the organization of the adjacent spaces in an effort to analyze how these structures were built to be loadbearing and to study the relationship between the covering structure and the spaces. The methodology of the article is based on an evaluation of the domed central baldachin construct of the selected structures and a description of the surrounding side spaces, after which the analogy technique is used to make comparison of all of the structures.

Mimar Sinan employed multiple-support systems of four, six or eight elements in his structural arrangement and one of the basic typologies he chose in his mosques was the square baldachin established on a square base. In the square baldachin system that signifies a differentiating typology of Sinan's mosques and is actually an experiment into central spatial organization, geometrical arrangements are different. Sinan has treated each square baldachin differently, both in terms of its installation and also in reference to its adjacent spaces, thus virtually creating a new typology in this group of structures. It can be said that this group represents a style that is uniquely Sinan's.

Mimar Sinan constructs the main spatial plan of his central square baldachin, single-domed mosques with four basic load-bearing elements-columns, piers, wall piers and corner walls. The central square baldachin is sometimes extended toward the east, west and sometimes to the north with side galleries (mahfil). The side spaces that Sinan used to expand the spatial construct were organically integrated with the central space. In Sinan's design, the integrated side galleries or mahfil add a composition that turns a cubic form into a square. The side spaces are also used to soften the effect of the overpowering structural composition of the dome. Sinan uses three basic constructs in these side galleries to surround the central space covered by the dome and soften the relationship between the load-bearing wall and the covering in the tradition of domed structures.

This concept was first implemented such that the side galleries (mahfil) were nestled into the depth of the area between the suspended arches carrying the dome and the outer walls as two-story structures that 
stand to the east, west and sometimes to the north, making up the square baldachin. In the second type of organization Sinan used in mosques of this typology, Sinan placed wall footings at the four corners of the structure so that the corner walls were connected with suspended arches, forming an exact or almost-exact square plan. The side galleries on the east, west and north were planted into the depth of the thickness of the arches in the form of two-story galleries (mahfil). The mosques in this category in which Koca Sinan uses a third concept for adjacent spaces have this time been designed as single-floor galleries on the east-west of the baldachins.

A common spatial characteristic in Mimar Sinan's structures of this typology can be seen in the way he approaches the facades of the buildings. Sinan paid particular attention to the facades of his buildings, especially to the frontality of his design. The facade was an essential element in his design of architectural masses. An examination of the facade organization Sinan employed in this group of mosques reveals that the facades are generally brought to life with suspended arches that form the square baldachin. The walls that are formed by windowed suspended arches are no longer load-bearing structures. The suspended arches, the curtain walls filled in with light and windows, comprise a system of facade that gives shape to the design of the outer mass of the building.

As can be seen in our analysis of the construct of the main and adjacent spaces in Mimar Sinan's single-domed square baldachin structures, of the load-bearing characteristics of these spaces and the spatial relationships between these, both the main spaces and also the spaces surrounding these central areas are differently interpreted in each one of Sinan's buildings. Sinan experimented with different spatial arrangments in each one of his works, never repeating himself but always providing a different construct for the baldachin and the surrounding side spaces in every building of the same type.

Always displaying an effort to find new stylistic variations to his buildings using available architectural elements, Sinan revealed a powerful experimental perspective and genius in every detail of his works. As in his entire body of works, in the structures in this particular group of buildings, Sinan exhibited an understanding of mass that enriched Turkish cities with new visual dimensions, introducing spatial arrangements in domed structures that created a unique Turkish mosque physiognomy.

Keywords: History of Art, Ottoman architecture, Architect Sinan, square baldachin, single-domed mosque.

Öz: Osmanlı'nın usta mimari Koca Sinan camii, hamam, medrese, mescit, han, kervansaray, darüşşifa, imaret, tabhane, darülkurra, sıbyan mektebi, su kemeri, tekke, çeşme ve saray gibi çok sayıda geniş tipolojide eser vermiş ve arkasında yaklaşık 400 e yakın eser bırakmıştır. Mimar Sinan'ın en çok üzerinde durduğu ve sayıca en fazla eseri camileridir. Başta payitaht Istanbul olmak üzere, imparatorluğun farklı yerlerine cami inşa etmiş olan Sinan hiçbir camiisinde aynı plan şemasını kullanmamış, kendisini tekrar etmemiş ve sürekli farklı plan denemelerinde bulunmuştur. Sinan'ın camilerinde kullandığı asal yapı elemanı kubbedir. O’nun camilerinde planı da belirleyen ana unsur olan kubbe hem tüm mekan bütününe hem de yapının dış plastiğine hakim konumda olan bir mimari elemandır. Bulunduğu şehirlerin kentsel silüetini de belirleyen ve yapının merkezi noktasında bulunan kubbe, Sinan camilerinde aynı zamanda bir imgedir. Mimari peyzajın önemli bir parçası olan camilerinde Sinan, kubbeli yapı geleneğine yeni bir kimlik kazandırmış ve bir mimari üslup geliştirmiştir. Sinan camilerinin plan kuruluşunu, onun kubbelerinde kullandığı strüktür özellikleri belirler. Kubbe strüktüründe 4, 6 ve 8 destek (baldaken) gibi çoklu mesnet sistemleri kullanan Mimar Sinan, bu sistemlerle oluşturduğu kubbeli yapılarda planı bu sistem çevresinde kurgular. Bu makalede Mimar Sinan'ın dörtlü baldaken sistemli tek kubbeli camiler grubuna giren beş camii (Edirnekapı Mihrimah Sultan, Eyüp Zal Mahmut Paşa, Lüleburgaz Sokullu Mehmet Paşa, Fatih Bali Paşa ve Manisa Muradiye) seçilmiş ve bu yapılarda kubbenin oturduğu merkezî kare baldaken sistemin kuruluşu ve etrafında gelişen yan mekân organizasyonu analiz edilmeye çalışılmıştır.

Anahtar Kelimeler: Sanat Tarihi, Osmanlı Mimarisi, Mimar Sinan, kare baldaken, tek kubbeli camiler.

\section{Giriş}

Osmanlı'nın usta mimari Koca Sinan camii, hamam, medrese, mescit, han, kervansaray, darüşşifa, imaret, tabhane, darülkurra, sıbyan mektebi, su kemeri, tekke, çeşme ve saray gibi çok 
sayıda geniş tipolojide eser vermiş ve arkasında çok sayıda eser bırakmıştır. Mimar Sinan'ın sayıca en fazla eseri camileridir. Başta payitaht Istanbul olmak üzere, imparatorluğun farklı yerlerine cami inşa etmiş olan Sinan'ın camilerinde kullandığı ana yapı elemanı kubbedir. O'nun camilerinde planı da belirleyen ana unsur olan kubbe hem tüm mekan bütününe hem de yapının dış plastiğine hakim konumda olan bir mimari elemandır. Bulunduğu şehirlerin kentsel silüetini de belirleyen ve yapının merkezi noktasında bulunan kubbe, Sinan camilerinde aynı zamanda bir imgedir. Mimari peyzajın önemli bir parçası olan camilerinde Sinan, kubbeli yapı geleneğine yeni bir kimlik kazandırmış ve bir mimari üslup geliştirmiştir (Özer 1987: 148). Denilebilir ki kubbeli yapı Sinan'ın elinde olgunlaşmış ve yeni bir anlam ve kimlik kazanmıştır.

Strüktürel ve simgesel bir örtü olan kubbe Sinan yapılarında başlıca mimari öğedir. Sinan'ın çok çeşitli denemeler gerçekleştirdiği camilerinde kullandığı kubbe kompozisyonları aynı zamanda bir mekan ve kütle biçimlendiricidir (Necipoğlu 2005: 69). İç mekana egemen olan kubbe Sinan yapılarında dış yapıyı da şekillendirir. Öyle ki kubbeli örtü artikülasyonu Sinan için bir mimari üsluptur. Kubbeli örtünün egemen olduğu bu üslup bir temel tasarım ilkesidir. Strüktürel biçimin ötesinde mimari kompozisyonu da oluşturan kubbe onun elinde yapıyla bütünleşmiştir. Kubbenin homojenliği ve biçimsel yalınlığ 1 onun yapılarında mekan etkisinin temel volumetrisine katkıda bulunur (Kuban 1988: 585). Kubbe ve iç mekan arasındaki görsel ve fiziksel ilişki mekan etkisini bütünler.

Mimar Koca Sinan için kubbe, hem merkezi tümel mekan yaratmak hem de simgesel bir etki oluşturma amacı olan çok amaçlı bir mimari elemandır. Kubbeli örtünün çok farklı ve çok zengin varyasyonlarını deneyen Sinan için kubbe sadece strüktürel bir öğe değildir. Osmanlı mimari üslubunun en önemli plan arketipi ve karakteristik öğesi olan kubbe onun için aynı zamanda mimari kompozisyonu taçlandıran, biçimsel bir öğedir.

Mimar Sinan Ağa camilerinde ölçekleri ve kullanıldığı yerler farklı olan kubbe varyasyonları kullanmıştır. Strüktürü ve işlevsel kullanışları farklı olan her camisinde, kubbeyi ve dolayısıyla mekanı farklı ele almıştır. Planı da belirleyen bu sistemde kubbe biçimci bir tutumla ele alınmıştır. Bu tasarımda strüktürel ilkeler ağır basar (Erzen 1988: 78). Temelde tektonik bir yaklaşım olan bu kurguda kubbe mekan düzeninin ana elemanıdır.

Sinan camilerinde mekanın çekirdeğini, kubbeli bir baldaken oluşturur. Bir strüktür sistemi olan baldaken mekan, mekanın üzerini örten kubbenin farklı sayıda ve çeşitlilikte taşıyıcıya (sütun, paye, duvar payesi, köşe duvarı) oturmasıyla oluşan mekan kurgusudur. Plan ve mekan bu baldakenin etrafinda gelişmiştir. Zengin bir mekan kurgusuna izin veren bu sistemde farkl1 mekânsal varyantlar yaratmak mümkündür. Camilerinde çok farklı kubbe strüktürü denemeleri yapan mimar Sinan'ın camilerinin plan kuruluşunu, onun kubbelerinde kullandığı strüktür özellikleri belirler. Kubbe strüktüründe dört, altı ve sekiz destek (baldaken) gibi çoklu mesnet sistemleri kullanan Mimar Sinan, bu sistemlerle oluşturduğu kubbeli yapılarda planı bu sistem çevresinde kurgular.

Bu makalede Mimar Sinan'ın dörtlü baldaken sistemli tek kubbeli camiler grubuna giren beş camii (Edirnekapı Mihrimah Sultan, Eyüp Zal Mahmut Paşa, Lüleburgaz Sokullu Mehmet Paşa, Fatih Bali Paşa ve Manisa Muradiye) seçilmiş ve bu yapılarda kubbenin oturduğu merkezî kare baldaken sistemin kuruluşu ve etrafında gelişen yan mekân organizasyonu analiz edilmeye çalışılmıştır.

\section{Kare Baldakenli Sinan Camileri}

Kubbeli baldaken strüktür düzeninde dört, altı ve sekiz destek gibi çoklu mesnet sistemleri kullanan Mimar Sinan'ın camilerinde kullandığı temel bir tipoloji de kare alt yapı üzerine kurduğu dört ayaklı baldaken mekan kurgusudur. Sinan camilerinde farklı bir tipoloji ve merkezi mekan denemesi olan dört ayaklı baldaken sistemde, yapının geometrik düzenlemesi de farklıdır (Tuluk 2006: 278). Sinan, kubbeli kare baldakeni hem baldakenin kuruluşu hem de yan hacimler 
açısından her yapısında farklı ele almış ve adeta bu grupta yeni bir tipoloji doğmasına neden olmuştur. Böylece bu grupta bir Sinan üslubu yaratmıştır.

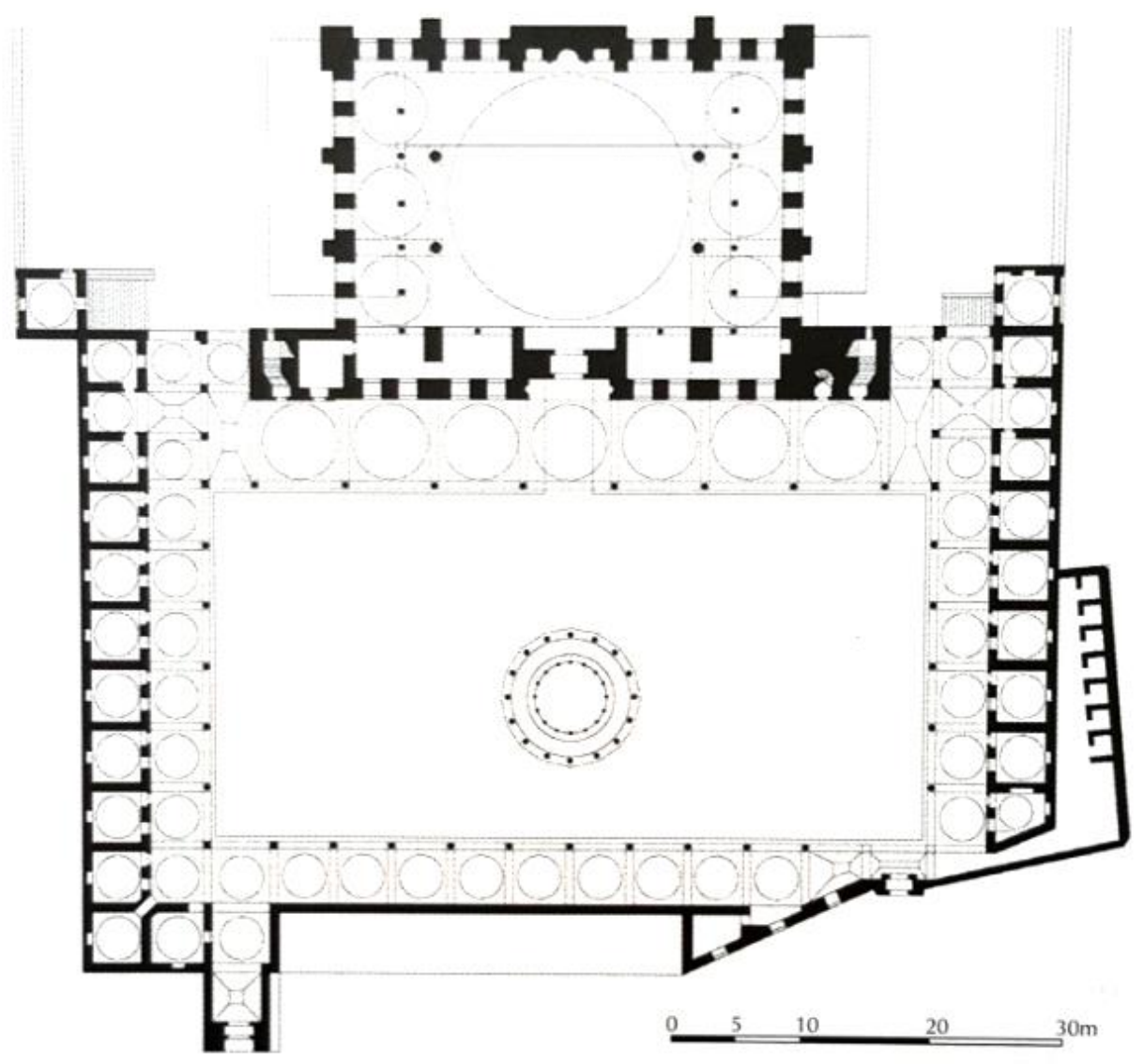

Şekil 1: Edirnekapı Mihrimah Sultan Camii Planı (Kuban 2007).

Sinan'ın kare tabanlı baldaken (dört ayaklı baldaken) sistemi kullandığı yapılarından çalışmamızda inceleyeceğimiz ilki Edirnekapı Mihrimah Sultan Camii’dir. Mimar Sinan'ın Kanuni Sultan Süleyman'ın kızı Mihrimah Sultan için 1562-1565 yılları arasında, Edirnekapı'da inşa ettiği yapı, mimarın biçim tasarımındaki yaratıcılığın ifadesidir. Yapının mimari kompozisyonu; önünde geniş bir avlusu olan, altı gözlü son cemaat yerli, enine gelișen yayvan bir plana ișaret eder. Sinan burada enine gelişen yayvan şemadaki yapının merkezinde; güneyde mihrabın iki yanında mihrap duvarına bitişik birer duvar payesi, kuzeyde ise girişin birer yanında, bu yöndeki duvara kemerlerle bağlanmış dört fil ayak ile kare bir baldaken oluşturmuştur (Şekil 1). Kare baldakeni oluşturan bu dört taşıyıcıyı ise birbirine dört askı kemerle bağlamıştır. Yapının merkezinde oluşan bu kare baldakenin üzerinde $25 \mathrm{~m}$. yüksekliğinde, $20 \mathrm{~m}$. çapında pandantifli bir kubbe bulunur. Bu kubbeli merkezi bölümü ise doğu-batı yönlerinden, kare baldakeni oluşturan ve kubbeyi taşıyan askı kemerler ile yapının dış duvarları arasında kalan alanın içine bir diğer ifade ile askı kemerlerin gerisine (derinliğine) yerleştirdiği, üst katı kadınlar mahfili olan, iki katlı, kubbeli, alçak birer galeri (yan mahfil) çevreler (Şekil 1-2). Bu mahfillerle (galeriler) mekan yanlara doğru genişletilmiş olur. Sinan burada merkezi, kubbeli baldaken sistemi, ana ayaklar ve ask1 kemerlerle birlikte yukarı doğru yükseltilmiş ve böylece merkezde taşıyıcılarla (ayak-kemer) birlikte yükseltilmiş kubbeli bir orta mekan ve iki yanda daha alçak bir galeri (yan mahfiller) kısmı ortaya çıkmış olur (Şekil 3). Bu 
yan galeriler kubbeli orta mekana, kare baldakeni oluşturan askı kemerlerin doğu-batı yöndeki ask1 kemerlerin içine yerleştirilen ve vaktiyle bu bölgede bulunan Ioannes Prodromos Manastırı'na ait olduğu rivayet edilen granit sütunların taşıdığı, simetrik üçer kemerle açılır (Kuban 1994: 455). Pandantifli kubbeyi taşıyan dört büyük askı kemerin üzeri (tympanon) ise yapıya maksimum ş̧ığı çekebilme kaygısı ile tüm yönlerde üç sıralı pencere ile doldurulmuştur. Böylece yapının dört yöndeki cephesi de kubbeyi taşıyan dört ayağı birbirine bağlayan, içi pencereli büyük ask1 kemerlerden oluşmuş olur. Sinan merkezi baldakende kullandığı içi pencereli kemer sistemi ile yarattığı aydınlık orta mekanı, yapının alçak yan galerilerinin cephelerinde de kullanmış ve böylece yapının içi ışığa doymuştur. Yapının mekan kurgusu ve strüktüründeki yeniliğin yanı sıra plastik tasarım gücü de hayli etkilidir.

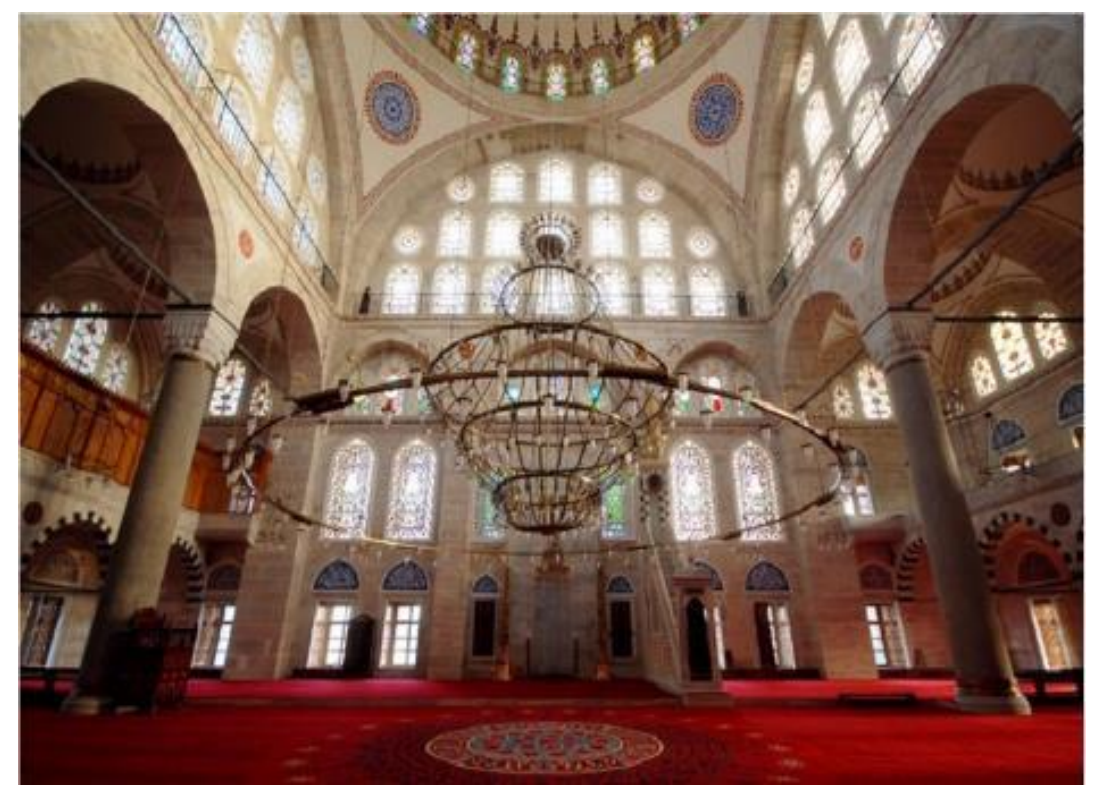

Şekil 2: Edirnekapı Mihrimah Sultan Camii İç Mekanı (Mustafa Cambaz).

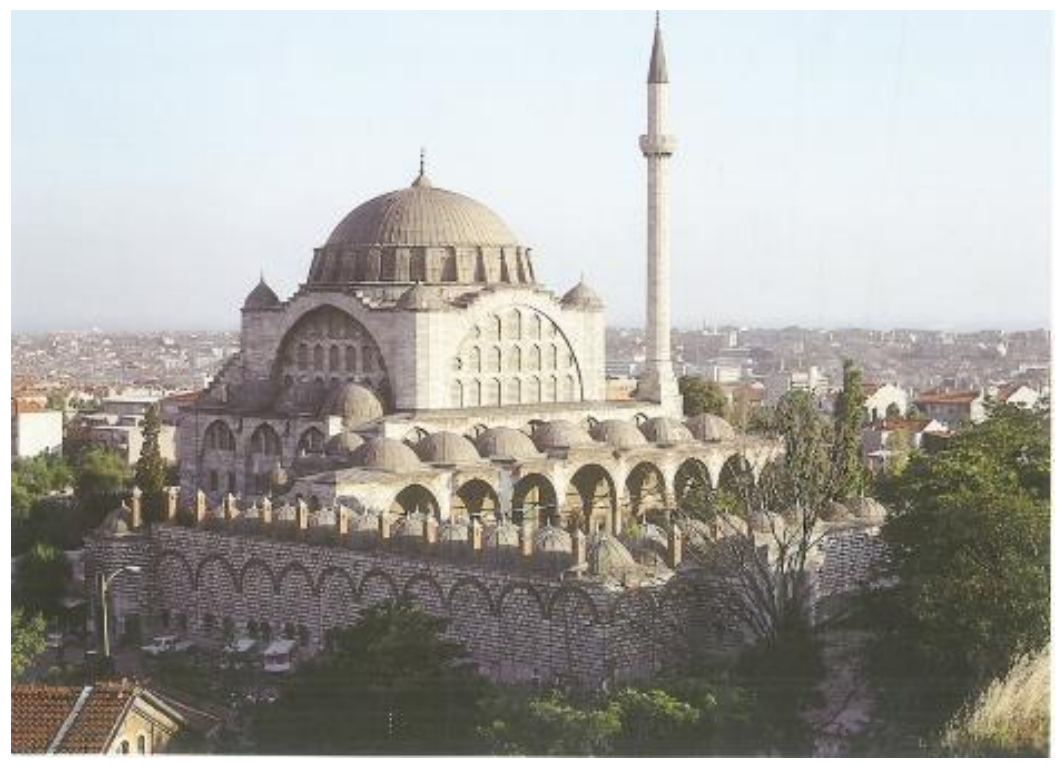

Şekil 3: Edirnekap1 Mihrimah Sultan Camii (Günay 2002, Fig 45).

Turkish Studies, 15(2) 
Mimar Koca Sinan'ın enine gelişen yayvan şemada kare baldaken kurguladığı bir diğer yapısı da Eyüp'de, II.Selim'in vezirlerinden Zal Mahmut Paşa ve eşi tarafindan, kesin tarihi belli olmamakla birlikte 1577 yılında yaptırılan Zal Mahmut Paşa Camii'dir. Sinan burada kare baldakeni, Edirnekapı Mihrimah Sultan Camii'nde olduğu gibi, ikisi mihrabın birer yanındaki duvar payelerine, diğer ikisi ise yapının kuzeyinde duvara yakın ve yine bu yöndeki duvara kemerle bağlanmış birer sütun olmak üzere dört taşıyıcı ile oluşturulmuştur (Şekil 4). Dört ana taşıyıcıyı ise birbirine yine dört büyük askı kemerle bağlamıştır. Oluşturduğu kare baldaken şemanın üzeri $12.40 \mathrm{~m}$. çapında pandantifli bir kubbe ile örtülüdür (Günay 1971: 98). Enine dikdörtgen plandaki yapıda dört ana taşıyıcıya oturan büyük askı kemerlerle oluşturulan kubbeli merkezi kare baldakenin etrafı ise doğu, batı ve kuzey olmak üzere bu kez üç yönden, üst katları kadınlara ayrılmış olan, iki katlı yan galerilerle (mahfil) çevrelenmektedir. Böylece merkezi kubbeli ana mekan üç yöne doğru genişletilmiştir. Sinan her üç yönde de iki katlı yan galerileri yine askı kemerler ile yapının dış duvarları arasında kalan alanın içine yani kare baldakeni oluşturan doğu, batı ve kuzey yönlerdeki büyük askı kemerlerin gerisine yerleştirmiştir (Şekil 5). Üç yönde kubbeli merkezi baldakeni çevreleyen yan mahfiller (galeriler) alt katta dörder sütunla desteklenir (Kuban 1994a: 542). Bu yan mekanların üzeri, kubbeden bağımsız olarak alt katta düz, üst katta aynalı tonoz ile örtülüdür. Sinan yapının beden duvarlarını (cepheleri) ise bu kez, mihrap cephesi hariç, askı kemerler yerine, üç kat pencereli düz duvar şeklinde tasarlamıştır. Yapının kubbesi dışta, yükselen bu yan duvarlar arasında adeta kaybolur (Akşit 2016: 67).

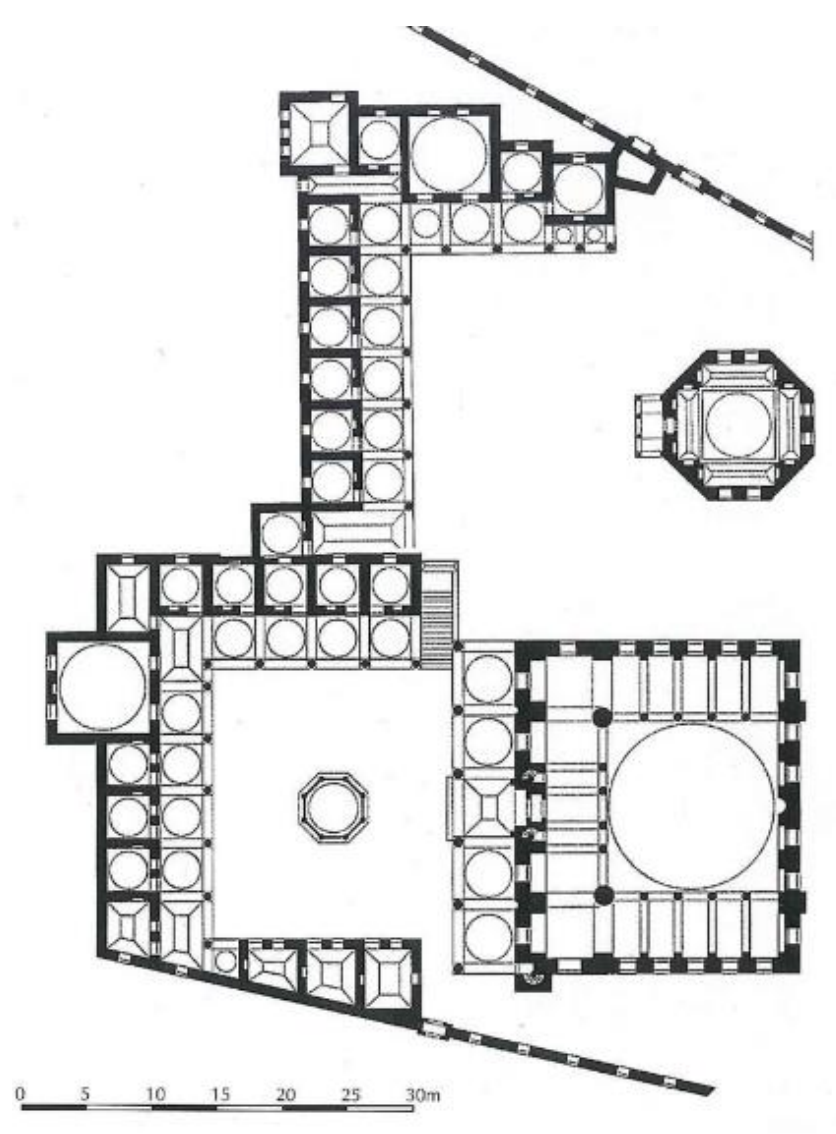

Şekil 4: Eyüp Zal Mahmut Paşa Camii Planı (Kuban 2007). 


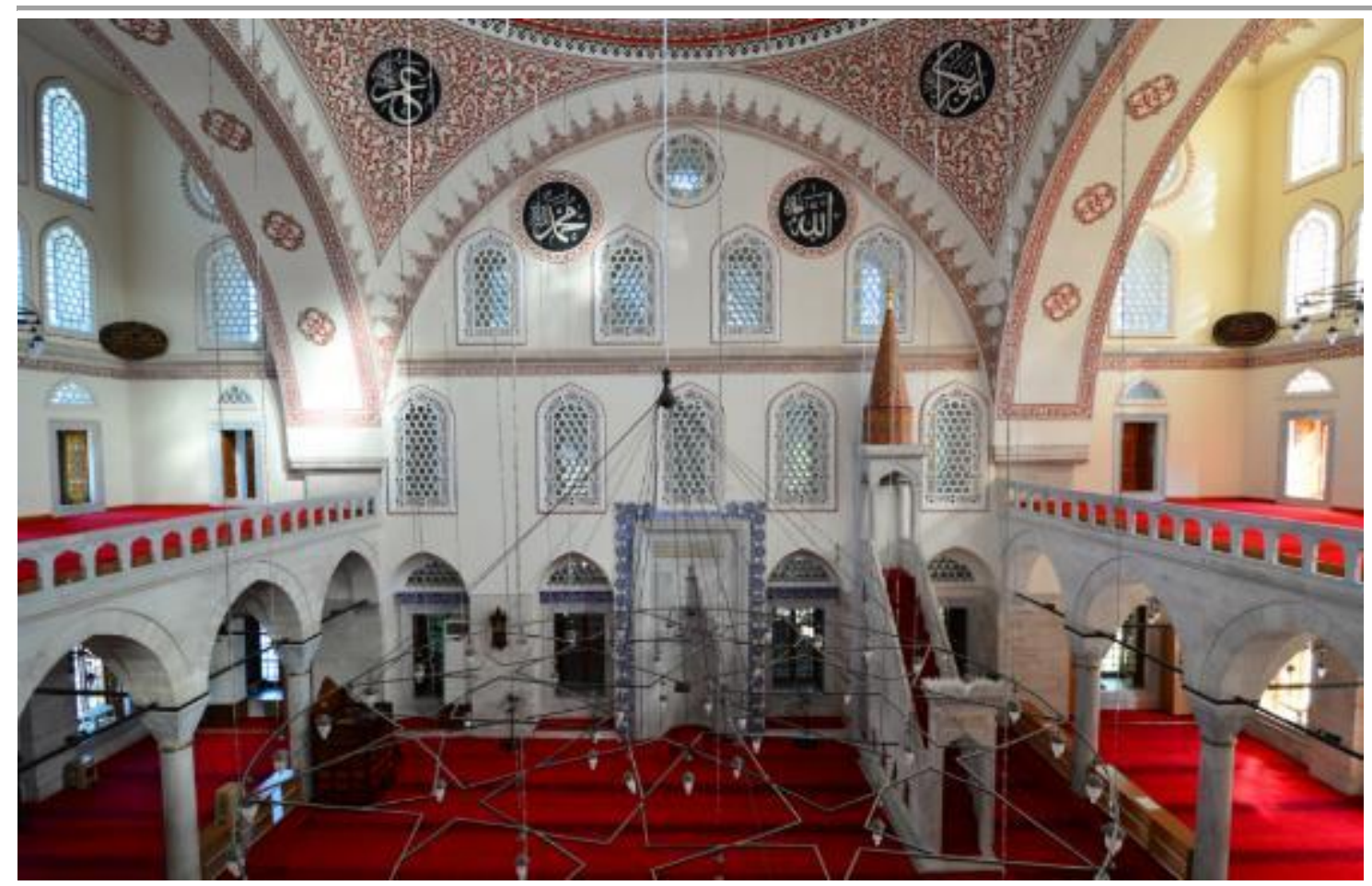

Şekil 5: Zal Mahmut Paşa Camii İç Mekanı (Sinan Doğan).

Osmanlı’nın usta mimarı Sinan 1569 yılında inşa ettiği bir menzil külliyesi olan Lüleburgaz Sokullu Mehmet Paşa Külliyesi Camii'nde kare baldaken kurgu ve yan mekan organizasyonunda bu kez farklı bir denemede bulunmuştur. Önünde geniş bir avlusu olan kareye yakın dikdörtgen plandaki yapıda Sinan bu kez kare baldakeni, önceki yapılarından farklı olarak, yapının dört köşesine yerleştirdiği 4.25 m. çapındaki fil ayaklarla kurar (Sönmezer, Ögel 2004: 77). Dört köşedeki dört fil ayak tüm yönlerde yapıdan taşar (Şekil 6). Fil ayakların üzerinde ise birer ağırlık kulesi bulunur. Ayaklar birbirine yine büyük askı kemerlerle bağlanmış olup oluşturulan kare baldakenin üzerinde $12.35 \mathrm{~m}$. çapında bir kubbe yükselir. Kubbeli, merkezi kare baldaken burada da doğu-batı yönlerine doğru, iki yan mahfille (sahın, galeri) genişletilmiştir. Ancak burada yan hacimler bu kez Edirnekapı Mihrimah Sultan ve Zal Mahmut Paşa Camii'nden farklı olarak, doğu-batı yönlerindeki askı kemerlerinin kemer kalınlığının içine (derinliğine) yerleştirilmiştir (Şekil 7). İki katlı yan sahınlar (mahfil, galeri) alt katta üç sütunla desteklenmektedir. Ask1 kemerlerden kuzey (giriş) yönündeki de derin tutulmuş olup onun derinliğine de minare kaidesi ve kadınlar mahfiline çıkan merdiven kovası yerleştirilmiştir (Kuran 1986: 43). Yapının beden duvarları (cephesi) ise dört yönde de yine ayakların arasındaki dolgu duvar olarak, içleri pencereli, merdivenli askı kemerlerden oluşur.

Mimar Sinan'ın kare baldakenli tek kubbeli bir diğer yapısı da I. Süleyman (Kanuni) döneminde inşa edilen Fatih Bali Paşa Camii'dir. Önünde beş gözlü bir son cemaat yeri olan yap1 bu kez tam bir karedir. Sinan kare baldakeni güney duvarı yönünde dıştan payandalarla desteklenen, dört köşedeki duvar payeleri ile oluşturmuştur (Şekil 8). Tüm mekanın üzerini örten $11.80 \mathrm{~m}$. çapındaki merkezi kubbe ise dört köşe duvarını birbirine bağlayan büyük askı kemerlere oturur (Eyice 1992: 21). Kare planlı yapıda Sinan yan mahfilleri ise, Lüleburgaz Sokullu Camii'nde olduğu gibi, yine doğu, batı ve kuzey yönlerinden askı kemerlerin derinliğine (kemer kalınlığının içine) yerleştirmiştir. Ancak bu kez mahfiller dar (sı̆̆) tutulan kemer kalınlığı nedeniyle son derece dardır (Şekil 9). İki katlı olarak tasarlanmış olan yan mahfiller (galeriler) önceki yapılarından farklı olarak, bu kez duvara bitiştirilmiş ikişer ayakla taşınmakta olup, alt katta ana mekana üçer kemerle 
açı1ır (Sözen 1975: 89). Yan galerilerin kadınlara ayrılmış olan üst katları yüksek korkuluklu kenarlıklarıla bir balkon görünümde iken alt katta ibadet alanı duvarlara bitiştirilmiş ayakları (paye) bağlayan sivri kemerlerin arasındaki, ancak tek kişinin namaz kılmasına izin veren dar alandır. Bu uygulamada kemerlerin arasındaki ibadet alanları, ayaklardan dolayı kesintiye uğradığı için bütüncül (homojen) bir yan mahfil görüntüsünden uzaktır.

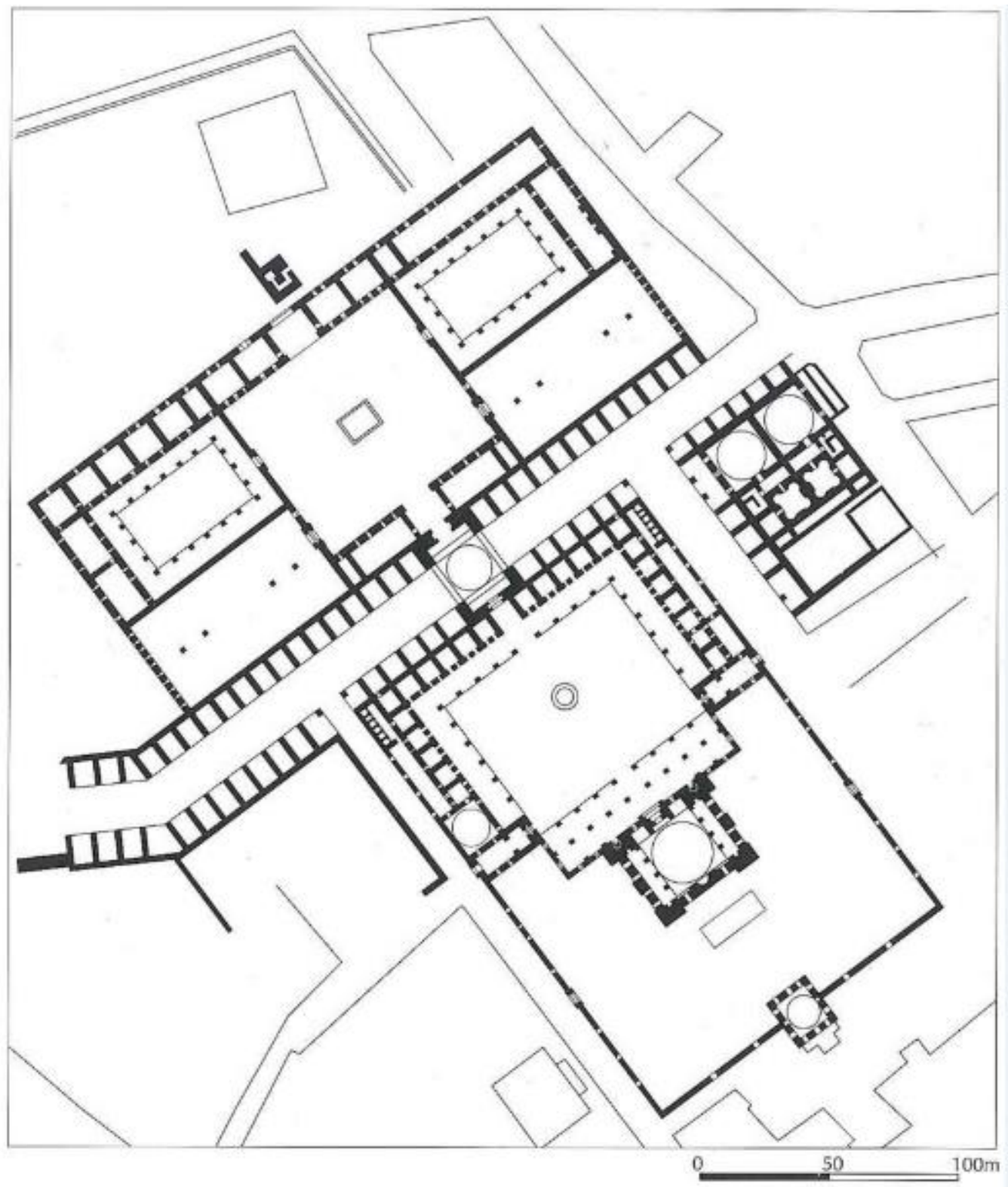

Şekil 6: Lüleburgaz Sokullu Külliyesi Camii Planı (Kuban 2007). 


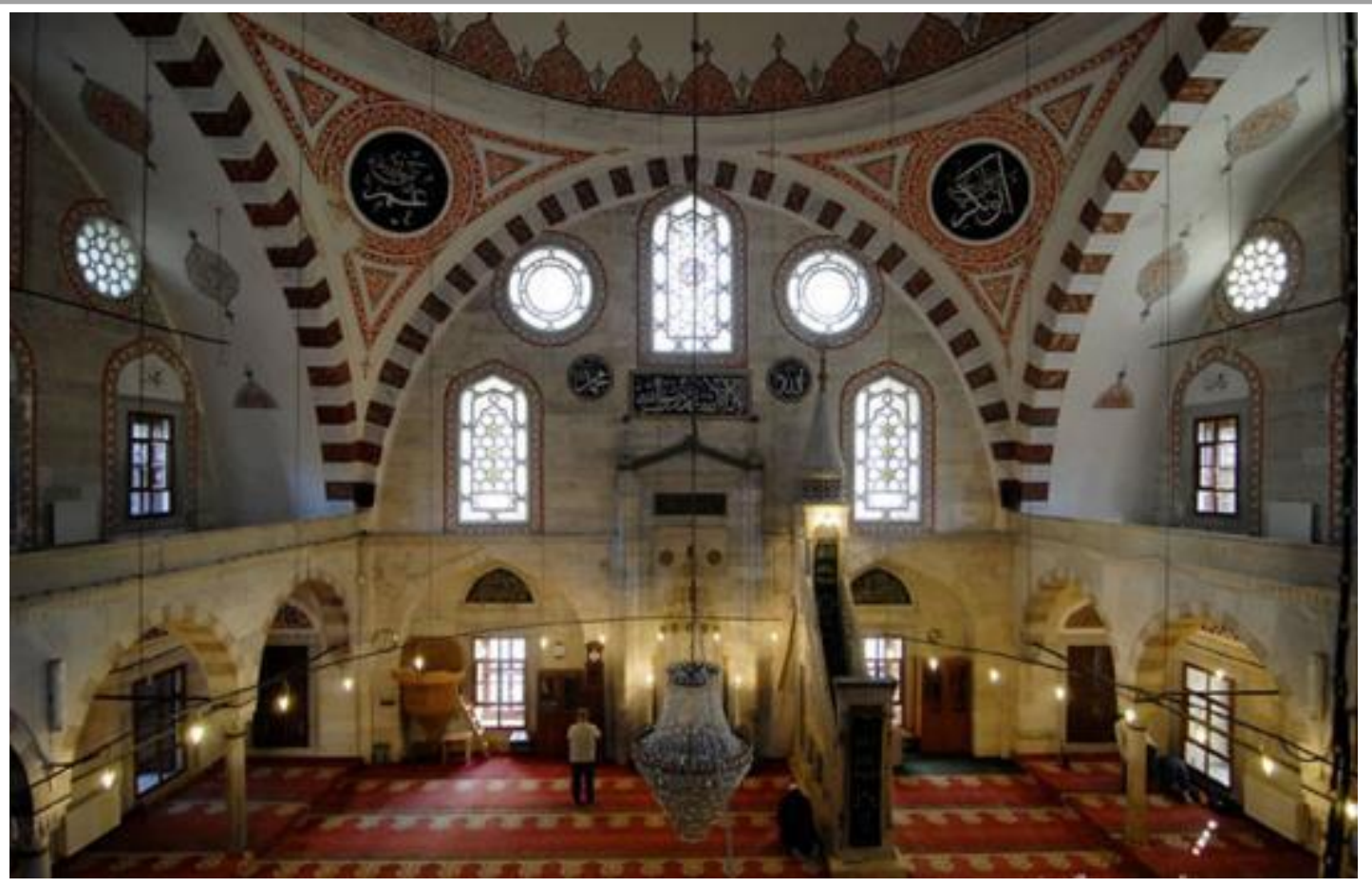

Şekil 7: Lüleburgaz Sokullu Külliyesi Camii İç Mekanı (Mustafa Cambaz)

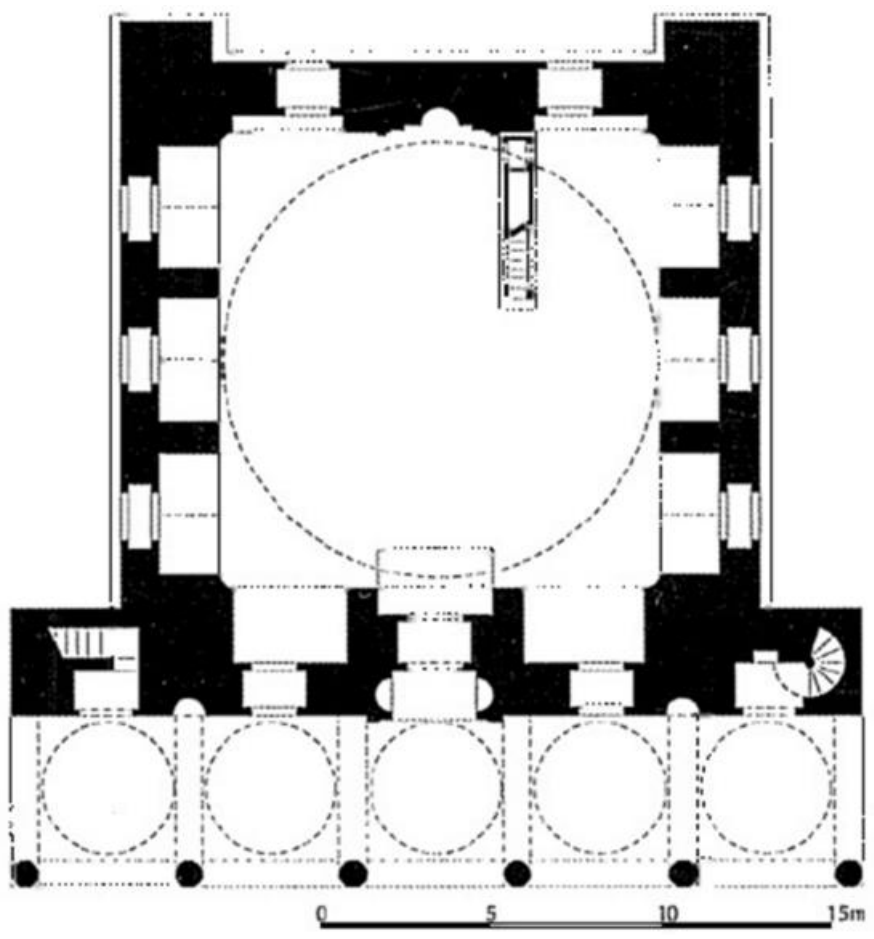

Şekil 8: Fatih Bali Paşa Camii Planı (Kuran 1986). 


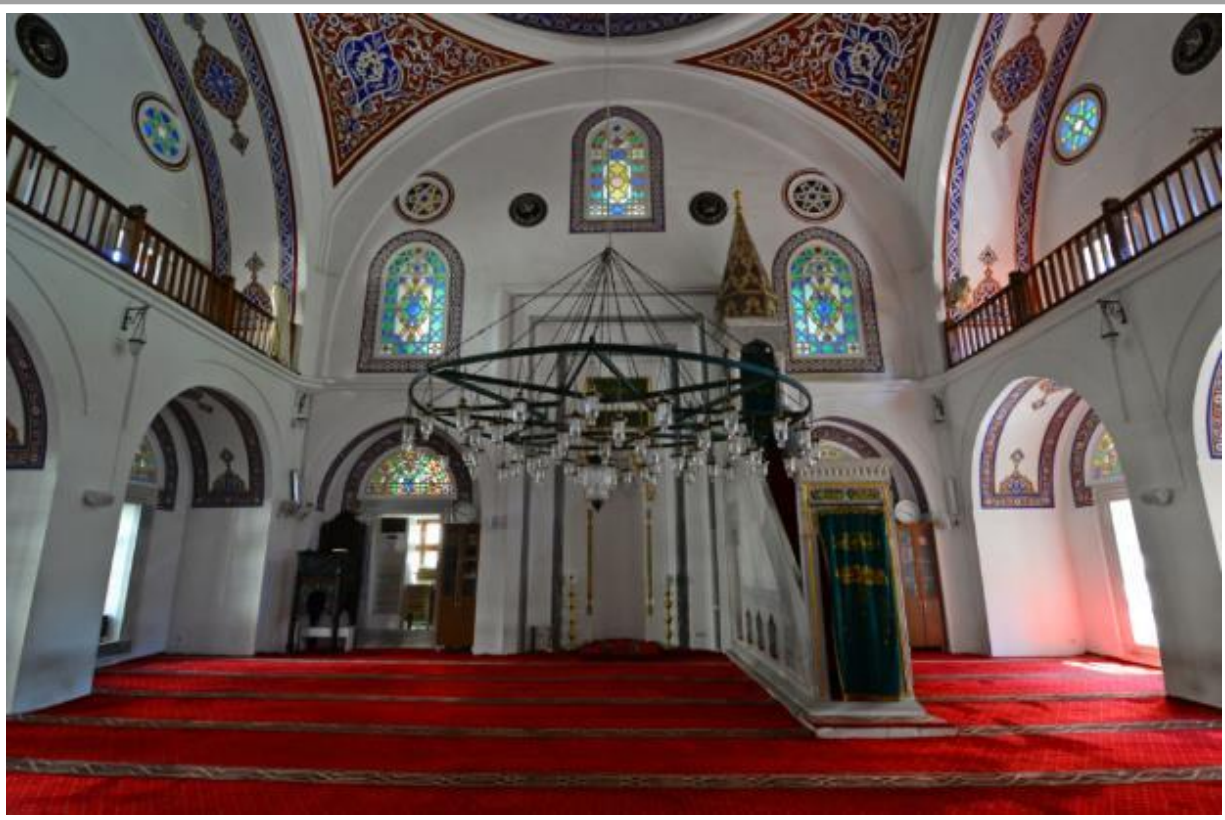

Şekil 9: Fatih Bali Paşa Camii İç Mekanı (Sinan Doğan).

Mimar Sinan'nın farklı bir kare baldaken kurgusu da Manisa Muradiye Camii'nde karşımıza çıkar. Sultan III.Murad adına Mimar Sinan tarafından 1583 yılında yaptırılan ve beş gözlü bir son cemaat yeri olan yapının mihrap bölümü, Tabhane planlı camilerde olduğu gibi yükseltilmiş zeminli, eyvan şeklinde dışa taşar (Şekil 10). Sinan bu yapıda kare baldakeni; ikisi güneyde mihrap eyvanın köşe duvarına, diğer ikisi ise kuzeyde girişin birer yanında olan, duvara gömülü olarak yerleştirdiği dört duvar payesi ile oluşturmuştur. Ayaklar birbirine yine geniş ask1 kemerlerle bağlanmış ve bu merkezi alanın üzeri pandantifli bir kubbeyle örtülmüştür. Merkezdeki kubbeli kare birim ise doğu ve batı yönlerine doğru yan mekanlarla genişletilmiş̧tir (Şekil 6). Sinan'ın bu kez tek katlı olarak bıraktığı bu yan mekanların (mahfil) üzeri ise yarım çapraz tonozla örtülüdür. Kubbeden bağımsız bu mekanların örtü sistemindeki farklılık, yapıya hareketli bir atmosfer kazandırmıştır. Böylece yapının mekan kurgusu kare planlı kubbeli baldakenin iki yana doğru tek katlı, yarım çapraz tonoz örtülü yan mekanlarla genişletilmesiyle oluşmuş olur. Yapının giriş yönünde ise üst katı kadınlara ayrılmış iki katlı bir mahfil (galeri) bulunur. Yapının tüm cepheleri yine pencereli şekilde tasarlanmıştır (Kuban 1988: 604; Goodwin 1971: 89).

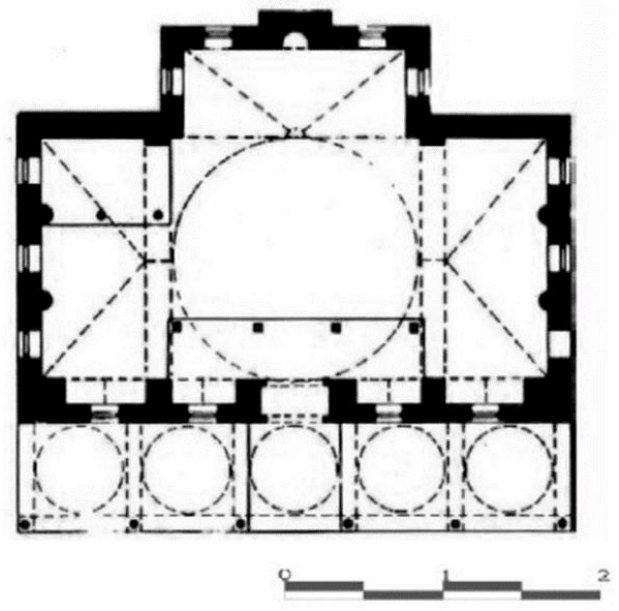

Şekil 10: Manisa Muradiye Camii Planı (Goodwin 1971). 


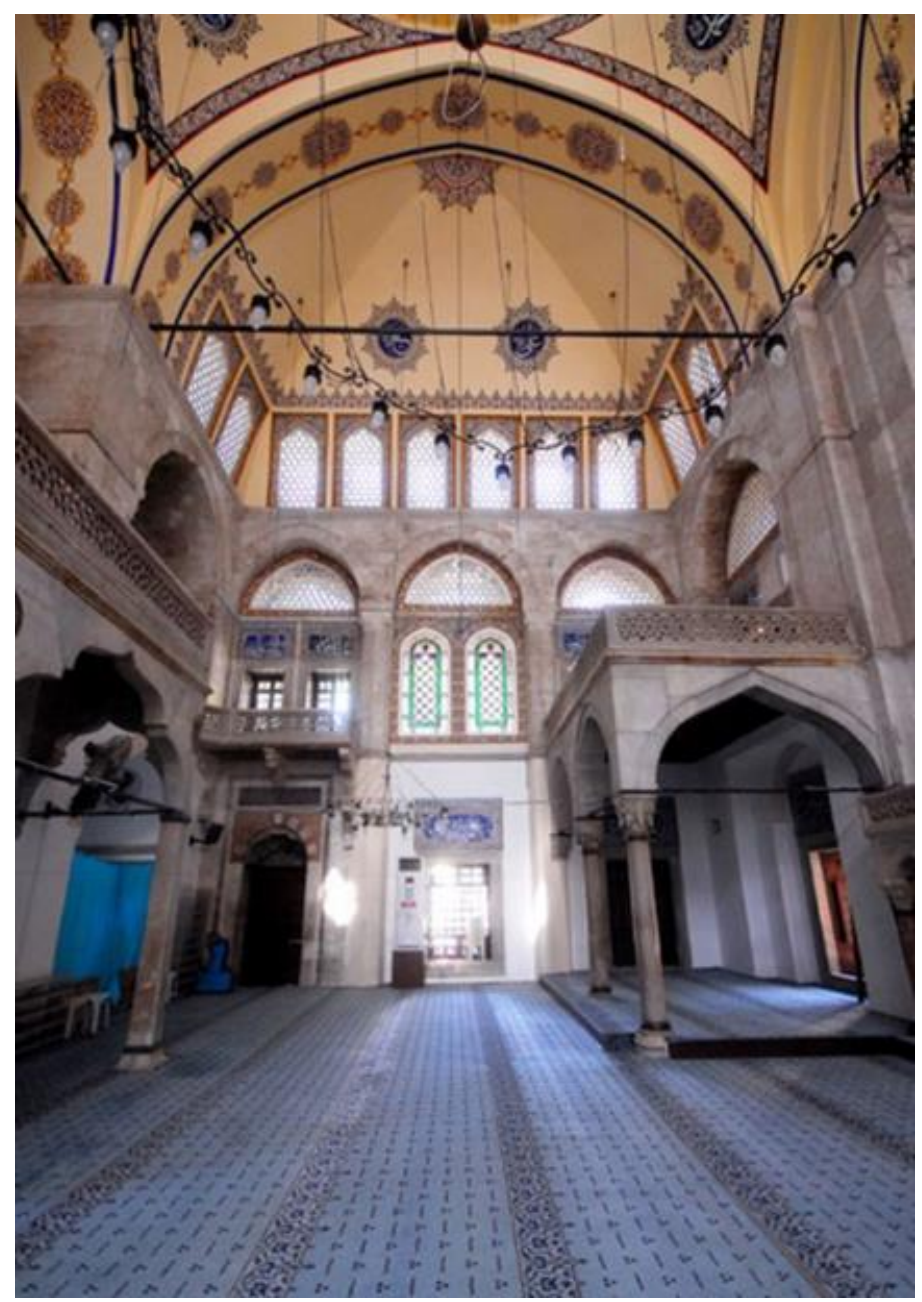

Şekil 11: Manisa Muradiye Camii Yan Mekan (Mustafa Cambaz).

\section{Ana Mekan-Yan Mekan Kurgusu}

Mimar Sinan'ın kare baldakenli, tek kubbeli camilerinde kurguladığı mekanlarda kullandığı ana plan arketipleri dört ana taşıyıcı (sütun, paye, duvar payesi, köşe duvarı), bu ana taşıyıcıları birbirine bağlayan dört büyük kemer (ask1 kemerler) ve bu kemerlerin doğu-batı yönlerinin gerisine yerleştirdiği yan hacimlerdir (mahfil).

Osmanlı'nın usta mimarı Koca Sinan kare baldakenli, tek kubbeli camilerinde ana mekanı oluşturan kare baldakeni iki şekilde kurar. Bunlardan Edirnekapı Mihrimah Sultan, Zal Mahmut Paşa ve Manisa Muradiye camilerinde kullandığı ilk kurguda, kare baldakeni enine gelişen yayvan şemadaki yapının içinde; güneyde ikisi mihrabın iki yanındaki duvarlara bitişik duvar payeleri, kuzeyde ise bazen girişin iki yanında duvarlara bitişik halde, bazen de bu yönde, mekanın içinde serbest bıraktığı ayaklarla kurar (Şekil 12). Duvar payeleri ve ayakları ise dört büyük ana kemerle birleştirir. Ana ayaklar ve onları bağlayan askı kemer sisteminden oluşan merkezi kare baldakenin üzeri ise genelde pandantifli bir kubbe ile örtülüdür. Bu kubbeli merkezi kare baldakenin etrafına ise iki veya üç yönden, mekanı genişleten yan mahfilleri yerleştirir. 


\begin{tabular}{|c|c|c|c|}
\hline $\begin{array}{c}\text { Edirnekapı Mihrimah } \\
\text { Sultan }\end{array}$ & $\begin{array}{c}\text { Eyüp Zal Mahmut } \\
\text { Paşa }\end{array}$ & $\begin{array}{c}\text { Lüleburgaz Sokullu } \\
\text { Mehmet Paşa }\end{array}$ & Fatih Bali Paşa \\
\hline Muradiye \\
\hline
\end{tabular}

Şekil 12: Incelenen Dörtlü Baldaken Sistemli Camiler.

Mimar Sinan'ın bu gruptaki yapılarında kullandığı ikinci ana mekan kurgusu Lüleburgaz Sokullu ve Fatih Bali Paşa Camii'ndeki ortak mekan kurgusudur. Sinan bu kez yapıları ya tam kare ya da kareye yakın dikdörtgen planda tasarlar ve kare baldakeni, yapının dört köşesindeki duvar payeleri veya köşe duvarları ile kurar. Tüm mekanın üzerini örten merkezi kubbeyi ise ayakları veya köşe duvarlarını birleştiren büyük askı kemerlere oturtur (Şekil 12).

Sinan bu tipolojideki camilerinde kubbeli kare baldakeni doğu, batı bazen de kuzey yönlerine doğru yan hacimlerle (mahfil, galeri) genişletir. Sinan'ın mekan genişletmek için kullandığı bu yan hacimler kubbeli merkezi mekanla organik olarak bütünleşmiştir. Bütünleşmiş yan galeriler (mahfil) Sinan'ın tasarımında yapıya küpten kareye doğru bir kompozisyon katar. Bu yan mekanlar ayrıca kubbe strüktürünün kompozisyondaki egemenliğini de yumuşatır (Kuban 2007: 455). Kubbeli yapı geleneğinde taşıyıcı duvarla örtü arasındaki ilişkiyi yumuşatan, kubbenin örttüğü merkezi hacmi çevreleyen bu yan hacimlerde (mahfil, galeri) Sinan üç temel kurgu kullanır. Bunlardan Edirnekapı Mihrimah Sultan ve Zal Mahmut Paşa camilerinde gördügümüz ilk konseptte; yan mekanları (mahfil, galeri) doğu, batı, bazen de kuzey yönlerinde, kare baldakeni oluşturan ve kubbeyi taşıyan askı kemerler ile yapının dış duvarları arasında kalan alanın içine yani askı kemerlerin gerisine (derinliğine), iki katlı olarak yerleştirir (Şekil 12). Bu yan mekanların üzeri, ana kubbeden bağımsız olarak Mihrimah Sultan Camii'nde küçük kubbeler ile örtülürken, Zal Mahmut Paşa Camii'nde alt katta düz, üst katta ise aynalı tonoz ile örtülüdür. Ana ve yan mekanlarda kullanılan farklı örtü sistemi yapıya bütüncül bir ana mekan görünümü vermez. Bu yan mekanlar alt katta ana mekana, doğu-batı yönündeki taşıyıcı ana kemerlerin arasındaki kemerlerle birleşir (Kuban 1997: 78). Sinan, bu grupta yer alan Edirnekapı Mihrimah Sultan Camii'nde ayrıca farklı bir düzenleme gerçekleştirmiş ve askı kemerler tarafından taşınan merkezi kubbeli kare baldakeni yukarı doğru yükseltip doğu-batı yönündeki iki katlı, kubbeli yan mekanları (mahfil, galeri) daha alçak tasarlanmıştır. Merkezi baldaken yan mekanlara, kare baldakeni oluşturan askı kemerlerin doğu-batı yöndekilerinin içine yerleştirilen sütunların taşıdığı kemerle açılır.

Sinan'ın bu tipolojideki camilerinde kullandığı ikinci yan mekan organizasyonu ise Lüleburgaz Sokullu ve Fatih Bali Paşa camilerinde görülür. Sinan bu iki camide de yapının dört köşesine yerleştirdiği duvar payeleri ve köşe duvarlarını birbirlerine yine askı kemerlerle bağlayarak tam veya yaklaşık kare plan oluşturmuş, yan mekanları da doğu, batı ve kuzey yönlerdekilerinde, bu kemerlerin kemer kalınlığının içine (derinliğine), iki katlı galeriler (mahfil) şeklinde kurmuştur (Şekil 12). Bu galeriler duvara bitiştirilmiş ikişer ayakla taşınmakta olup, alt atta ana mekana ayakları bağlayan kemerle açılır. Bu kemerlerin arasındaki dar alanlar ise ibadet 
alanı olarak kullanılır. Bu kez duvara bitişik olarak tasarladığı ayakları bağlayan kemerlerin arasındaki ibadet alanları ayaklardan dolayı kesintiye uğradığı için yine mekana bütüncül bir yan mahfil havasi vermez.

Koca Sinan Ağa'nın bu kategorideki camilerinde kullandığı üçüncü yan mekan konseptinde ise bu kez kare baldakenin doğu-batı yönündeki yan mekanlar tek katlı olarak kurgulanmıştır. Bu kurguyu kullandığı tek camisi olan Manisa Muradiye Camii'nde, merkezdeki kubbeli kare baldakenin doğu-batı yöndeki askı kemerlerin gerisinde bulunan ve yine bu kemerlerin derin bırakılmasıyla oluşan alanın içine yapılan yan mekanlar bu kez kat katlı olarak planlanmıştır (Resim 12). Sinan burada yan mekanların üzerini kubbeden bağımsız olarak, yarım çapraz tonozlarla örtmüş ve kubbeden bağımsız olan bu mekanların üst örtü sistemindeki farklılık, yapıya hareketli bir atmosfer kazandırmıştır.

Mimar Sinan'ın kare baldakenli tek kubbeli yapılarındaki ortak bir mekan özelliği de cepheleri ele alışıdır. Sinan için yapının cephesi özel olarak düşünülmüş olup cephelerin ele alınışında frontalite onun için dikkat edilmesi gereken önemli bir nokta idi. Örtüden zemine kadar hareketli bir duvar tasarımı gerçekleştirir (Kuban 2007: 267). Cephe onun için kütle tasarımının vazgeçilmezidir (Freely 2011: 89). Sinan'ın bu gruptaki camilerinde kullandığı cephe organizasyonu incelendiğinde cephelerin genelde kare baldakeni oluşturan askı kemerlerden oluştuğu görülür (Esemenli 1990: 52). Özellikle Edirnekapı Mihrimah Sultan Camii'nde izlenen bu uygulamada, yapının yükseltilmiş kubbeli orta mekanının dört yöndeki cephesini, kare baldakeni oluşturan ayakları birbirine bağlayan askı kemerler oluşturmaktadır (Şekil 12). Bu haliyle yapı, yığma bir yap1 için sıra dışı bir görünüme kavuşmuş ve dört yöndeki ayak sistemi ile ask1 kemerlerin oluşturduğu duvarlar artık taşıyıcı duvar olmaktan çıkmıştır. Pencereli askı kemerlerden oluşan cephe kurgusunun bir diğer örneği de Lüleburgaz Sokullu Külliyesi Camii'nde görülür. Burada yapının beden duvarları (cephesi) dört yönde de ayakların arasındaki dolgu duvar olarak, içleri pencereli askı kemerlerden oluşur. Pencereli, 1şıklı askı kemerlerden oluşan dolgu duvarlı cephe sistemi yapının dış kütle tasarımını da biçimlendirir.

\section{Sonuç}

Mimar Sinan'ın dörtlü baldaken sistemli, iki ve üç yöne genişleyen yan mekanlı camilerinde, kubbenin oturduğu merkezî kare baldaken sistemin kuruluşu ve etrafinda gelişen yan mekân organizasyonun irdelendiği bu makalede görüldüğü gibi, Sinan bu gruptaki her yapısında hem dörtlü baldakeni hem de etrafindaki yan mekanları farkı çözümlerle kurgular. Türk mimarlığında kubbeli strüktürün gelişim çizgisi içerisinde önemli bir yeri olan dörtlü baldaken sistemli tek kubbeli camilerinde Sinan, mekan kuruluşunda kare prizmatik mekanın üzerini örten kubbe ve üst örtü ile ilişkili yan hacimler ile merkezi mekan yolunda önemli bir adım atar. Kubbenin duvarlar tarafından taşındığı cami çizgisinde önemli bir aşama gerçekleştiren Koca Sinan kare baldakenin örtüsü olan kubbeyi farklı mesnetli ayaklara oturtarak onu beden duvarlarından kurtarmıştır.

Sinan bu gruptaki camilerinde içten ve dıştan yapıya hakim motif olan kubbeli örtü ile merkezi mekanı taçlandırır. Toplu mekan ile oluşturulan mekan bütünlügünde kubbenin yükünü taşıyan ayakların konumuna özel önem gösterir. Kubbeli merkezi mekan kimliğine yeni boyutlar kazandıran Mimar Sinan farklı ayak sistemi varyantları ile mekanı ve kitleyi biçimlendirir. Zengin bir mekân organizasyonuna izin veren kare baldaken sistemde taşıyıcı kompozisyonları ile farklı mekânsal tipolojiler yaratır. Sinan kare baldaken sistemde mekanı genişletmek için kullandığı yan mahfil ve ana mekan bütünleşmesinde bile yaratıcılı̆̆ına işaret eden farklı konseptler dener. Karenin içinde yer alan taşıyıcılardan oluşan merkezi ana mekan ile onu iki veya üç yönden kuşatan tek veya iki katlı mahfillerden oluşan iç mekan düzeni ile Sinan tek kubbeli bir harim mekanının nasıl zenginleşebileceğini ortaya koyar. 
Sinan'ın tüm yapılarında olduğu gibi bu gruptaki yapılarında da amaç, mekan tasarımında kubbeyi doğrudan algılamaktır. Biçimsel ve simgesel bir öğe olarak kullandığı kubbeli örtüye dayanan mimari tasarımı onun kişisel ustalığını ortaya koyar. Kare tabanlı çardakta varılabilecek en ideal şemaya ulaşan Sinan, kubbeli ana mekan ile çevresindeki mekanı bütünleştirmiştir. Kubbeli mekanı çevreleyen ikincil mekanlar orta hacimle birleşir. Sinan bu yapılarda da dolu duvar geleneği yerine pencereli dolgu duvar sistemini tercih eder.

Yaptığı gözlemlerle, edindiği tecrübeleri her yapısında farklı kurgulayan Sinan, yapılarında yeni mimari öğelerle değil tersine kalıpları belirlenmiş alışılageldik geleneksel öğelerle çalışmıştır (Kuban 1988: 604). Ancak hiçbir yapısında bir öğeyi birebir kullanmaz mutlaka kendisinden bir şeyler katarak o elemanı yorumlar. Mevcut mimari elemanlarla oluşturduğu yeni biçim arayışları hep devam etmiştir. Her yapısında aynı elemanlarla farklı denemelerinde bulunur ve kendini tekrar etmez. Her detayda onun deney gücü ve dehası kendini gösterir. Oluşturduğu kütle anlayışı ile Türk şehirlerine yeni görsel boyutlar kazandıran mimar Sinan, kubbeli mekan strüktüründe yarattığ1 mekanlar ile oluşturduğu Türk camii fizyonomisi ile bir "Sinan sentezi" yaratmıştır.

\section{Kaynakça}

Akşit, İ. (2016). Architect Sinan - His Life, Works and Patrons. Istanbul: Akşit Yayınc1lık.

Aslanapa, O. (1986). Osmanlı Devri Mimarisi. Istanbul: Ink1lap Kitabevi.

Aslanapa, O. (1993). Türk Sanatı. Istanbul: Remzi Kitabevi.

Erarslan, A. (2018). “Mimar Sinan'ın Altıgen Baldaken Sistemli Camilerinde Taşıyıcı, Örtü ve Mekan İlişkisi." Osmanlı Mirası Araştırmaları Dergisi (OMAD) Cilt 5, Sayı 13: 31-48.

Erzen, J. (1988). “Sinan as Anti-Classicist.” Muqarnas 5: 70-87.

Esemenli, D. (1990). "Baldaken Formlu Camilerin Geç Osmanlı Devrindeki Dış Görünümleri Üzerine.” Sanat Tarihi Araştırmaları Dergisi 3/8: 49-57.

Eyice, S. (1988). "Mimar Sinan'ın Külliyeleri." VI. Vakıf Haftası. Türk Vakıf Medeniyeti Çerçevesinde Mimar Sinan ve Dönemi Sempozyumu, 5-8 Aralık 1988. Istanbul: İstanbul, Vakıflar Genel Müdürlüğü Yayınları, 169-200.

Eyice, S. (1992). "Bali Paşa Cami.” TDV İslam Ansiklopedisi 5: 21-22.

Freely, J. (2011). A History of Ottoman Architecture. UK: WIT Press.

Goodwin, G. (1971). A History of Ottoman Architecture, London: Thames Hudson.

Günay, R. (2002). Mimar Sinan. Istanbul: YEM Yayınları.

Kuban, D. (1988). “Sinan'ın Dünya Mimarisindeki Yeri.” Mimar Başı Koca Sinan. Yaşadığı Çağ ve Eserleri. Istanbul: TC Vakıflar Genel Müdürlüğü. 581-624.

Kuban, D. (1994). "Mihrimah Sultan Külliyesi.” Dünden Bugüne İstanbul Ansiklopedisi 5: 454456.

Kuban, D. (1994a). “Zal Mahmut Paşa Külliyesi.” Dünden Bugüne İstanbul Ansiklopedisi 7: 54243.

Kuban, D. (1997). “The Style of Sinan's Domed Structure.” Muqarnas 4: 72-97.

Kuban, D. (2007). Osmanl Mimarisi. Istanbul: Yem Yayınları.

Kuran, A. (1986). Mimar Sinan. Istanbul: Hürriyet Vakfi Yayınları. 
Necipoğlu, G. (2005). The Age of Sinan: Architectural Culture in the Ottoman Empire. Princeton and Oxford: Princeton University Press.

Özer, B. (1987). "The Architect of Domed Mosques as a Master of Pluralism.” Environmental Design: Journal of the Islamic Environmental Design Research Centre 1-2. (Der.) Attilio Petruccioli, Rome: Carucci. 146-155.

Sönmezer, Ş., Semra, Ö. (2004). "Lüleburgaz Sokullu Mehmed Paşa Camii’nde Oran-Strüktür İlişkisi." itüdergisi/a mimarlık, planlama, tasarım 3/1: 75-79.

Sözen, M. (1975). Türk Mimarisinin Gelişimi ve Mimar Sinan. Istanbul: Türkiye İş Bankası Kültür Yayınları.

Tuluk, Ö. I. (2006). "Osmanlı Camilerinde Mekan Kurgusu Açısından Kare Tabanlı Baldaken Varyasyonları." Gazi Üniv. Müh. Mim. Fak. Der. 21/2: 275-284. 